\title{
POBREZA URBANA E A FORMAÇÃO DE BAIRROS POPULARES EM SALVADOR NA LONGA DURAÇÃO
}

\author{
Pedro de Almeida Vasconcelos*
}

\section{RESUMO:}

O artigo é dividido em duas partes. A primeira parte trata da discussão do conceito de pobreza, com destaque para as noções de marginalidade, de underclass e de exclusão e pobreza urbana. Na segunda parte é comentada a situação dos pobres em Salvador e a formação dos bairros populares na longa duração (1549-2005), seguindo uma periodização em oito etapas, em conformidade com o meu livro sobre as transformações e permanências em Salvador (2002.).

PALAVRAS-CHAVE:

marginalidade, pobreza urbana, exclusão, bairros populares.

\section{RESUMÉ:}

L'article comprend deux parties. La première discute le concept de la pauvreté, en particulier les notions de marginalité, underclass, exclusion et pauvreté urbaine. La situation des pauvres et la formation des quartiers populaires à Salvador, pendant la longue durée (15492005), sont analysées dans la deuxième partie, suivant une périodisation en huit étapes, conformément à mon livre sur les transformations et permanences à Salvador (2002).

KEY WORDS:

marginalité, pouvreté urbaine, exclusion, quarties populaires.

\section{Introdução}

É necessário, em primeiro lugar, discutir conceitualmente a questão de pobreza, devido a sua relatividade no tempo e no espaço ${ }^{1}$. Em seguida será discutida a formação de bairros populares em Salvador, com base, sobretudo na minha pesquisa sobre as transformações espaciais na cidade, na longa duração ${ }^{2}$, assim como na pesquisa em desenvolvimento realizada sobre o patrocínio do CNPq.
A questão da pobreza foi discutida, sobretudo na Sociologia. Na Geografia, a grande exceção foi a contribuição de Milton Santos, que, além da discussão sobre os dois circuitos da economia urbana, elaborou um livro intitulado Pobreza Urbana em 1978, no qual, além de realizar um balanço teórico sobre a questão, trouxe uma extensa bibliografia internacional sobre a temática. 


\section{Discussão Conceitual}

Segundo o historiador Geremek, existiriam três visões da miséria na Idade Média: a primeira seria a dos pobres virtuosos, por renúncia; a segunda, a dos verdadeiros miseráveis, os velhos, os fracos e os doentes que não podiam se manter; a terceira, a dos que podiam trabalhar, mas não queriam, como os bandidos, os vagabundos e os criminosos ${ }^{3}$.

$\mathrm{Na}$ Sociologia a discussão sobre a pobreza tem uma grande tradição. No seu livro clássico de 1944, Polanyi informa o aparecimento da pobreza na Inglaterra na primeira metade do século $\mathrm{XVI}^{4}$, causada pela destruição da velha ordem social com o desenvolvimento da economia de mercado. Comenta, também, que a Poor Law Amendment, de 1834, teria dividido os pobres em indigentes e trabalhadores independentes, e que teria sido criada uma nova categoria de pobres: os desempregados ${ }^{5}$.

Robert Castel, outra referência na temática, cita Tocqueville, que teve sua tese sobre o pauperismo publicada em 1986, que estabelece a diferença entre a "pobreza integrada" numa sociedade pré-industrial como a de Portugal, e a indigência persistente na Inglaterra pós-revolução industrial ${ }^{6}$.

Uma das definições possíveis do pobre seria "aquele indivíduo que não pode obter os bens de primeira necessidade, como a alimentação, alojamento e vestuário" 7. De fato, a noção de pobreza é relativa, pois ela varia no tempo e no espaço. Quem era considerado pobre no século XVI não seria o mesmo no século atual. A mesma coisa pode-se comentar sobre os diferentes espaços: ser pobre nos Estados Unidos não é a mesma coisa de ser pobre no Brasil. Outro aspecto destacado é que a pobreza pode transformar-se em exclusão quando o nível dos recursos é muito baixo para participar da vida social (problemas de saúde, fracasso escolar, dificuldades de trabalho $)^{8}$.
Didier Fassin discute a origem de três noções ligadas à pobreza urbana e seus contextos originais: a "marginalidade" (América Latina), que estaria ligada à relação centro / periferia; o "underclass" (Estados Unidos), que trataria da relação hierárquica alto / baixo"; e a de "exclusão" (França), que privilegiaria as relações dentro / fora. Para o autor, a questão da marginalidade estava ligada à situação das periferias das cidades latino-americanas e ela mantinha um paralelo com as noções de países centrais / periféricos. A marginalidade teria a ver com as frações crescentes da população que não encontrariam lugar no sistema capitalista ${ }^{10}$. As explicações teriam sido tanto marxistas, segundo as quais a realidade cultural estaria ligada às contradições do modo de produção capitalista (quando cita autores como Nun e Quijano); ou explicações culturalistas, a partir de traços psicosociais pelos quais se caracterizam os indivíduos (com citações de autores da Escola de Chicago e de O. Lewis). Haveria, também, três dimensões: (1) a econômica (ausência de salário regular e proteção social); (2) a dimensão espacial (bairros periféricos) e (3) o domínio político (populismo e clientelismo). Finalmente, o autor faz a relação entre marginalidade e setor informal ${ }^{11}$.

De fato, Oscar Lewis considerava a Cultura da Pobreza como um modo de vida passado de uma geração para a outra. As principais características seriam: (1) falta de participação e integração do pobre nas principais instituições da sociedade; (2) um mínimo de organização além do nível familiar; (3) ausência de infância como um estágio prolongado e protegido no ciclo de vida; (4) um sentimento forte de marginalidade: abandono, dependência e inferioridade ${ }^{12}$.

No Brasil, a tese de Kowarick resume a questão da marginalidade. Segundo o autor a marginalidade aparece como problema teórico e prático após a Segunda 
Guerra Mundial ${ }^{13}$, sendo a marginalidade o fruto do processo de acumulação capitalista ${ }^{14}$. O autor considerou como marginais os trabalhadores no artesanato, os autônomos no comércio e na prestação dos serviços pessoais, e as atividades domésticas ${ }^{15}$.

No seu livro, Janice Perlman considerou a marginalidade como um mito baseando-se nos seguintes argumentos: os favelados e suburbanos (1) socialmente, eram organizados e coesivos; (2) culturalmente, eram otimistas e aspiravam uma melhor educação para suas crianças e melhores condições para suas moradias; (3) economicamente, eles trabalhavam muito, consumiam e construíam suas casas e a infra-estrutura comunitária; e (4) politicamente, não eram apáticos nem radicais $^{16}$.

A noção de underclass foi discutida criticamente por Wacquant. Para o sociólogo francês, "mais do que uma categoria sociológica, é um categorema: um instrumento de acusação pública"17. Os pobres dos bairros segregados, por sua conduta, estilo de vida e valores "disfuncionais", seriam os responsáveis pelo declínio da cidade ${ }^{18}$. O desemprego, o recurso à assistência social, a desorganização conjugal e anomia sexual, o fracasso escolar, o encarceramento, o tráfico e o consumo de drogas, a delinqüência de rua e a criminalidade violenta seriam características do underclass $^{19}$. Três visões foram destacadas pelo autor: (1) a posição estrutural: exclusão racial, rejeição das instituições oficiais como a escola e a expulsão do assalariamento; (2) os comportamentos anti-sociais; (3) a concepção neoecológica: fim dos empregos sem qualificação e efeitos da desindustrialização nos bairros. Ao mesmo tempo, o autor faz a distinção entre "conceitos folclóricos", que seriam usados pelos administradores públicos, autoridades e pela população, dos "conceitos analíticos" que a pesquisa social deveria construir, alertando para "a circulação internacional de conceitos falsos, como o de "underclass", ... inadequados para serem importados" 20 .
Paugam, por seu lado, comenta a exclusão e a pobreza urbana na Europa: as famílias pobres seriam 26,5\% em Portugal, $14,9 \%$ na França e 4,2\% na Dinamarca ${ }^{21}$. Quanto ao número de pobres, eles seriam mais de 12 milhões na Itália e apenas 200.000 na Dinamarca. Haveria três tipos de pobreza: (1) a pobreza integrada: exemplo, o sul da Itália, onde o setor público é valorizado e é complementado por atividades no setor informal; (2) a pobreza marginal: com o caso da Suécia, onde apenas $6 \%$ dependiam da assistência social; (3) a pobreza desqualificante ou seja, a da exclusão: como no caso da Inglaterra, com $17,4 \%$ da população dependendo da assistência social ${ }^{22}$.

Na Geografia, o livro de Milton Santos, Pobreza Urbana, comenta, inicialmente, a dificuldade de definir a pobreza, e o autor cita a definição de Lewis, de 1969, como a "incapacidade de satisfazer as necessidades do tipo material" 23 . Em seguida, critica as explicações parciais da pobreza urbana através da explosão demográfica e do êxodo rural, da falta de capital doméstico, da "cultura da pobreza" e o debate entre crescimento e desenvolvimento. Comenta, também, a questão da marginalidade e da bipolarização quando trata dos dois circuitos da economia urbana, que serão comparados com o "setor informal". Conclui com as relações entre as teorias do desenvolvimento e a pobreza. Uma rica bibliografia, com 883 títulos sobre a temática, é apresentada no referido livro.

O exame do caso do Brasil, e especificamente do de Salvador na longa duração, é de interesse, na medida em que um contingente importante da população estaria hoje na condição de pobreza, e a dimensão espacial da pobreza poderia ser examinada através da formação de bairros populares.

\section{A formação dos bairros populares em Salvador}

As divisões de bairro normalmente não são precisas, tendo origem tanto em antigas 
freguesias, quanto até em novos loteamentos ou conjuntos habitacionais de grande porte.

O bairro pode ser definido como "uma categoria particular de ser geográfico, que provém do 'espaço vivido' de uma certa comunidade de pertencimento e de uma representação dela" 24, ou como "parte do núcleo urbano relativamente homogêneo, com limites mais ou menos imprecisos, que constitui uma unidade básica na percepção da vida urbana" 25 .

Vamos utilizar a mesma periodização realizada no estudo de 2002 sobre Salvador ${ }^{26}$, para destacar a questão da pobreza urbana e da formação dos bairros populares nesta cidade.

Uma primeira constatação é a de que a pobreza urbana antecede a formação de bairros populares em Salvador.

Quem seriam os primeiros "pobres" em Salvador, numa sociedade escravista? Os escravos, africanos e seus descendentes, em si mesmo, formavam uma categoria com estatuto jurídico próprio, independente de seu conteúdo desumano. Os indígenas também contavam com a proteção da Igreja e com a legislação específica da Coroa portuguesa.

Por outro lado, em Portugal, e conseqüentemente nos territórios da Coroa portuguesa havia a diferença, numa sociedade senhorial, entre os nobres e os "piões", que, podiam, inclusive receber castigos físicos e serem obrigados a trabalhos forçados, o que os aproximavam dos escravos. Neste sentido, entre os não nobres vindos de Portugal, os indivíduos sem bens nem capitais, a maioria tinha dificuldades para vender sua força de trabalho numa sociedade escravista (onde a quase totalidade do trabalho manual era realizado pelos escravos) e, ao mesmo tempo, não tinha recursos para a compra de escravos. Esses portugueses poderiam formar os primeiros contingentes de pobres urbanos. Os artesãos portugueses, que também realizavam atividades manuais, logo começaram a adquirir escravos para ensinar os ofícios que passariam a ser realizados pelos mesmos.

Outra categoria que terá seus contingentes ampliados será a dos libertos, ou seja, dos escravos alforriados durante o período escravista, que teriam de sobreviver, assumindo a responsabilidade de se alimentar e de se alojar, a si próprio ou à família.

Os mestiços de portugueses e indígenas ou de africanos, além dos filhos dos portugueses nascidos na América portuguesa, passariam a formar a futura população "nacional".

\section{9-1650: A implantação da "cabeça de ponte"}

Nesse primeiro período, Salvador era uma pequena cidade, cuja população estimada, no final do período, era de apenas 10.000 almas. Fernão Cardim, contemporâneo desse período, estimava que, em 1583, Salvador tinha 3.000 vizinhos portugueses, 8.000 índios e 3 a 4.000 escravos de Guiné ${ }^{77}$. Ou seja, a pequena sociedade era mais dividida pelos seus componentes raciais do que pelas primeiras divisões de classe. Por outro lado, a pequena dimensão da cidade não permitia ainda uma separação entre os bairros pobres e os demais bairros. Os mapas elaborados no período mostram que a cidade extrapolava um pouco o sítio original com avanços em direção ao norte (Carmo) e ao sul (São Bento). Sobre o entorno da cidade, temos informações de Soares de Souza de que estava ocupado por roças pertencentes a casais portugueses. Os índios foram concentrados em algumas aldeias em torno da cidade, mas seu número foi reduzido drasticamente: Anchieta, em 1583, informou, que, em 20 anos, das 40.000 almas reunidas pela ordem na Bahia, restavam apenas 3.500 índios $^{28}$. Quanto aos negros, quilombos já teriam sido detectados em 1575 na orla atlântica e outro foi destruído no Rio Vermelho em $1632^{29}$.

O estabelecimento da Santa Casa da Misericórdia, logo após a fundação da cidade, trouxe para Salvador uma instituição 
filantrópica que se ocupará dos pobres: dote para moças pobres, alimentação de prisioneiros, enterros e hospital que atendia inclusive aos escravos.

Por outro lado aparecem as primeiras referências aos pobres: já em 1641 a Câmara Municipal procurava um remédio contra a 'cantidade de pobres que andavão mendigar nesta cidade" 30 .

\section{0-1763: A idade de ouro de Salvador}

Esse é o período "áureo" de Salvador. Uma hipótese avançada é que o mesmo é resultante não tanto da acumulação originária da exportação do açúcar, em parte aplicada nos próprios engenhos e capelas, mas, sobretudo, dos resultados do tráfico de escravos e da venda dos mesmos e do contrabando do ouro com Minas Gerais.

A cidade crescera, e a população, no final do período, era quatro vezes maior do que no seu início. No frontispício de Caldas (1759) a área ocupada da cidade vai da Soledade até o São Bento, embora já esteja indicado o forte de São Pedro.

Censos do período, como o de 1718 e 1724 , registram que quase a metade (49\%) da população era composta por escravos, estando mais da metade dos mesmos (52\%) concentrados nas duas freguesias centrais: Sé e Conceição da Praia31. A presença escrava, inclusive nas atividades de rua (ganho), dominava a questão da pobreza.

Os relatórios elaborados pelos vigários em 1757 nos dão algumas informações sobre o conteúdo social de algumas áreas de Salvador: na freguesia de São Pedro, no lado sul, foi informado que "Compõem-se esta Matriz de soldados ... de gente de pouca utilidade, sendo os nobres poucos, por não haverem nesta Matriz grandes edifícios por ser a mayor parte cazas pequenas ... térreas" . A freguesia do Passo, no lado norte "he bem povoada com boas cazas ...". $\mathrm{Na}$ enorme freguesia de Santo Antônio, situada ao norte e a leste do centro, o vigário comentou: "toda povoada de rossas, a maior parte della de pessoas moradores na cidade que beneficiam as ditas rossas com alguns escravos ..., até o rio ... Camarugipe, cujo logar é .... cituado de varias rossas, a maior parte dellas de homens pretos libertos ...", uma primeira referência sobre a localização periférica dos ex-escravos da cidade. O mesmo vigário mencionou que Itapagipe de Baixo era uma "povoação de pescadores" e Itapagipe de Cima "cujo lugar é cituado de alguns Pescadores, e de varias rocinhas, de alguns de varias pessoas moradores na cidade nas quaes tem alguns escravos" 32 .

Em 1711, porém, a população pobre revoltou-se contra as taxas e os preços do sal, o que indica uma primeira participação política ${ }^{33}$.

\section{3-1823: Capital de capitania}

Esse período é iniciado com a transferência da capital colonial para o Rio de Janeiro, mas Salvador continuou como a principal cidade da América Portuguesa. As estimativas de população variam de 60.000 habitantes em 1768 a 115.000 habitantes em 1818. Os mapas do período mostram um adensamento da ocupação urbana e um crescimento em direção ao leste, com a abertura de novos bairros como o de Barris.

Em 1771 temos outra indicação indireta da pobreza, em documento que menciona que 300 negros, mestiços e brancos se ocupavam da pesca da baleia, sobretudo na ilha de Itaparica, mas causavam impacto em Salvador, porque nos " 3 ou 4 meses que dura aquela pescaria, despovoa-se grande parte da cidade, ... porque toda a pobreza se acha naquele tráfico"'34.

$\mathrm{Na}$ cidade, o sistema clientelista funcionava em torno das famílias mais abonadas: residiam nos mesmos prédios, além da família propriamente dita com seus escravos, também agregados com seus escravos próprios $^{35}$. Na freguesia de São Pedro, por exemplo, segundo o censo de 1775, em 671 propriedades, correspondendo a 707 fogos, 
havia 2.689 residentes, sendo 523 "pais de família", 627 mulheres, filhos e filhas, 403 agregados, 73 mulheres e filhas de agregados e 985 escravos $(39,5 \%)$, dos quais 78 eram escravos dos agregados ${ }^{36}$. Dos "pais de família" $66,6 \%$ eram brancos, $15,7 \%$ mestiços e $17,7 \%$ eram negros. Dos 347 "pais de família" brancos, 40 foram registrados como pobres e 24 não tinham profissão. Dos 274 agregados brancos, 65 foram classificados como "sem profissão" e 17 como pobres; dos 82 "pais de família" mestiços, oito não tinham profissão e 10 eram pobres; entre os 92 "pais de família", pretos, 11 eram pobres ${ }^{37}$.

Esses dados preciosos indicam tanto a proximidade residencial entre os diferentes grupos étnicos, com proporções semelhantes de pobres entre os diferentes grupos de cor, assim como a inserção de uma minoria de pobres em uma freguesia perto do centro atual.

No mesmo ano foi estabelecida uma postura sobre arruamentos, determinando a localização dos mercadores e artesãos na cidade: aos primeiros estavam reservados os espaços mais centrais, seguidos pelos principais ofícios, enquanto que os barbeiros deveriam se localizar na periferia leste da cidade $^{38}$.

Vilhena testemunhou a pobreza dominante em Salvador, no final do século XVIII:

Todo o povo, à exceção dos comerciantes e alguns lavradores aparatosos ... é uma congregação de pobres, pois além de serem muito poucas as artes mecânicas e fábricas em que possam empregar-se, ... o não fazem pelo ócio que professam, e a conseqüência que daqui pode tirarse, é que infalivelmente hão de ser pobríssimos 39 .

O professor ainda destacou que os mendigos eram brancos, mestiços e negros. Os primeiros eram, sobretudo, marinheiros e antigas prostitutas. Os negros e mestiços eram os cegos, aleijados, velhos e estropiados libertos $^{40}$. O professor destacou que a freguesia de Santo Antônio tinha edifícios "de menos suposição em número e qualidade" ${ }^{41}$, indicando um declínio da direção norte.

O contrabandista inglês Lindley, que esteve em Salvador no período de 1802 a 1803, comentou a situação dos pobres: "a classe mais baixa, constituída de soldados, mulatos e negros, vive em choças cobertas de telhas e sem forro, dotadas de uma única janela de rótula ..." 42,0 que foi confirmado pelo comerciante francês Tollenare, que esteve na Bahia, em 1817: "quando se percorre os arrabaldes e os bairros retirados causa admiração ver ali o formigar de uma imensa população de brasileiros livres, aglomerados em casinhas miseráveis. Toda esta gente vive de quase nada e anda pouco vestida ..." 43 . Esse viajante também comentou que o Rio Vermelho era um povoado de pescadores. Outra testemunha, a inglesa Maria Graham comentou: "as cabanas dos pobres são feitas de estacas verticais com galhos de árvore trançados ... cobertos e revestidos seja com folhas de coqueiros, seja com barro. Os tetos são cobertos de palha"44.

Quilombos foram ainda detectados neste período: o do Buraco do Tatu, em 1763, os de Mares e Cabula, em 1807. Também data do período a Sedição dos Alfaiates, que teve uma grande participação de mestiços, assim como de movimento popular contra a carestia em 1811 e os primeiros levantes africanos em 1807, 1809 , 1813 e 1814, em sua maior parte realizados por escravos haussás ${ }^{45}$.

1823-1850 - Salvador no império instabilidade e africanização

Esse período é marcado pelas instabilidades iniciais no novo Império, com o agravante dos resultados da guerra da independência e dos importantes levantes realizados pelos africanos, assim como da grave rebelião da "Sabinada". No final do período, com a aproximação do final do tráfico, ocorreu a maior entrada de escravos africanos.

As estimativas de população são ainda precárias: 48.240 escravos foram levantados 
em 1833, e 54.652 habitantes livres em 1848 46, o que confirma a importância dos escravos na cidade, sem destacar a presença de libertos.

O vice-consul Wetherell, comentou em 1845, as diversas possibilidades de utilização dos escravos urbanos:

em numerosos casos a posse ou o uso de escravos é o único meio com que o brasileiro conta para a sua subsistência ...; a finalidade real dos escravos para a maioria dos habitantes: alugá-los como trabalhadores ou domésticos ...; o dono obriga o escravo a pagar-lhe a quantia de, digamos um xelim por dia, e tudo o que o escravo conseguir ganhar mais dessa soma ... fica sendo de sua propriedade $^{47}$.

Enquanto os escravos domésticos residiam junto aos senhores, os de ganho podiam residir longe do controle dos proprietários.

O mapa de Weyll, publicado em 1851, retratando a realidade da década anterior, mostra a cidade desde Itapagipe até o Rio Vermelho, e é o primeiro que destaca as áreas periféricas da cidade, registrando as primeiras ocupações de bairros atuais de Salvador (Nazaré, Matatu, Quinta das Beatas, Estrada das Boiadas, Cruz do Cosme, Retiro etc.).

\section{0-1889 - Salvador no império - Estabilidades e infra-estrutura}

Ao contrário do período anterior, o final do império foi um período estável, e o final do tráfico dos escravos, em 1850, deslocou recursos para a infra-estruturação da cidade, que contou também com investimentos estrangeiros, como o da implantação da única ferrovia de Salvador, concluída em 1860, pelos ingleses. As primeiras linhas de transporte urbano, com tração animal, começam a funcionar em 1851, o que vai permitir a expansão da cidade.

Pelo censo de 1872 , Salvador tinha 129.000 habitantes, sendo $68,9 \%$ negros e mestiços e apenas $12 \%$ de escravos, o que indica a importante liberação ocorrida no período que antecede o final da escravidão. Pelos dados do censo, os mestiços e negros estavam concentrados nas freguesias do Passo (85\%), Penha (75,6\%), São Pedro (74\%), Vitória $(73,5 \%)$, Santo Antônio (73\%) e Sé $(69,5 \%)$, mas deve ser observado que os escravos estavam concentrados em três freguesias: São Pedro (18,8\%), Vitória $(17,9 \%)$ e Sé $(16,8 \%)^{48}$, o que indica que a maior concentração de exescravos e seus descendentes estava nas freguesias do norte de Salvador. Katia Mattoso destacou que a maioria dos libertos era pobre ou muito pobre, a partir dos testamentos examinados ${ }^{49}$.

Em 1855 foi inaugurado um dormitório de mendigos no convento de São Francisco ${ }^{50}$ e em 1860 a Ordem Terceira de São Francisco inaugurou o Asilo Santa Isabel ${ }^{51}$, revelando a continuação do papel filantrópico das instituições religiosas no período.

Em 1845, o vice-cônsul Wetherell criticou a sociedade baiana : "a classe baixa dos brancos ... preferem aceitar pequenas situações governamentais mal pagas, ou até mesmo roubar ou desfraudar ..." Quanto às residências dos negros, certamente residência dos libertos, comentou: "os barracões dos pretos são dos mais primitivos ... são feitos de canas de bambus entrelaçadas com lianas flexíveis ... O teto é coberto com folhas de palmeiras ...; o assoalho é a própria terra batida" 52 , descrição semelhante à de Maria Graham no final do período colonial.

Em 1861, o viajante francês Mouchez destacou «population de ces ruelles ... nègres, matelots, portefaix, ... de nombreux mendiants tous plus ou moins lepreux étalant d'horribles plaies ... $\gg^{53}$.

Antes da abolição, portanto, havia uma mistura residencial, embora as freguesias do sul concentrassem um maior número de escravos, enquanto que os livres e libertos de cor já estavam situados nas freguesias ao norte, ainda que perto da área central. 


\section{Salvador na República - reformas urbanas e europeização}

Este período, iniciado com os impactos da abolição da escravidão e com o início da república, traz as contradições de uma busca do modelo europeu de urbanização (com as reformas urbanas) e do abandono da população de origem escrava.

A ampliação e a melhoria dos transportes urbanos, com a implantação dos bondes elétricos, vai permitir a expansão das áreas construídas da cidade.

Com a abolição, uma massa de exescravos se deslocou do campo em direção a Salvador, que, adicionando-se aos ex-escravos urbanos, levará a ampliação das casas de cômodo e cortiços nas áreas centrais e ao adensamento das áreas periféricas

A população de Salvador cresceu lentamente neste período: passou de 174.412 habitantes em 1890, para 205.813 em 1900, 242.176 em 1910, 283.422 em 1920 e 290.000 em 1940, tendo sido ultrapassada por São Paulo (1900) e Recife (1940).

A cidade foi "modernizada" com a inauguração da energia elétrica, início de saneamento, e, sobretudo, as reformas urbanas no governo de J. J. Seabra (1912-1916), que transformaram parcialmente a área central, da parte alta da cidade, duplicaram a área portuária, juntamente com a ampliação do porto e deram início ao desenvolvimento da parte sul da cidade com a abertura da avenida Sete de Setembro.

A implantação das linhas de bondes elétricos veio melhorar a acessibilidade dos bairros, valorizando as vias de cumeadas, o que leva a formação de bairros em "escadaria". Os primeiros loteamentos datam deste período (1925).

Data, também, desse período a implantação de indústrias têxteis (uma com 1.600 operários), e a criação das primeiras vilas operárias. Nesse sentido, aparecem os esboços dos primeiros bairros operários (Itapagipe, Plataforma, etc.). Mapas dos anos 40 confirmam o adensamento e crescimento dos bairros da Penha, Liberdade, de Quintas e de Brotas, que formavam a periferia da cidade na época. A abertura da orla atlântica data também deste período, com a avenida Oceânica (1912-1922) e a ligação Amaralina - Itapuã (1942).

Donald Pierson realizou uma primeira "topografia social" da cidade, nos anos 30, com a indicação das predominâncias de habitantes por cor: os bairros de Mata Escura, Engenho Velho, Federação, Garcia, Quintas da Barra, Retiro, Alto do Abacaxi, Alto das Pombas, Estrada da Liberdade, Estrada da Rodagem, Cabrito, Cruz do Cosme, Matatu Pequeno eram habitados, predominantemente, por negros e mestiços escuros; Santo Antônio, Barbalho, Barris, Tororó e Itapagipe por mestiços; e Vitória, Canela, Graça e Barra por brancos ${ }^{54}$. Em 1920, Santo Antônio passa a ser a freguesia mais populosa de Salvador, com 56.000 habitantes ${ }^{55}$.

No período do governo Vargas, além da consolidação da legislação trabalhista, destacase a criação dos institutos de aposentadoria e pensão dos diversos segmentos trabalhistas e a implantação dos conjuntos habitacionais correspondentes (IAPI, IAPSEB etc.).

\section{5-1969 - Pré-metropolização: Migrações e grande expamsão}

Este é um dos principais períodos de desenvolvimento dos bairros populares em Salvador devido às grandes migrações regionais ocorridas e o conseqüente crescimento demográfico. Pode ser adicionado o impacto positivo causado pelo início das atividades da Petrobrás na região, seguido pela implantação do Centro Industrial de Aratu.

As grandes invasões datam do início deste período: Corta Braço (Pero Vaz), Alagados, Nordeste, Boca do Rio, entre outras.

O planejamento municipal, através do 
EPUCS (1943-1947), estabelece um zoneamento da cidade em diferentes áreas funcionais, consolidando a zona industrial na área de Itapagipe, e define áreas, como a de São Caetano, como "setor residencial operário". O Estado amplia suas atividades, a partir de 1964, com o início da implantação dos programas habitacionais do $\mathrm{BNH}$.

Outra grande transformação realizada no período é o lançamento de centenas de loteamentos, sobretudo ao longo da orla atlântica (128 projetos nos anos 50 e 47 nos anos $60^{56}$ ). Loteamentos populares foram também implantados, sobretudo em Lobato e nos subúrbios ferroviários. Além desses projetos, começaram a ser detectados loteamentos clandestinos no território municipal. Os loteamentos serão articulados pelos ônibus, após a extinção das linhas de bondes em 1961.

Em 1950, Salvador contou com 417.235 habitantes, sendo $41,5 \%$ pardos e $24,7 \%$ negros, sendo $41,5 \%$ analfabetos. O crescimento foi migratório, em $70 \%{ }^{57}$. Pesquisas publicadas por T. Azevedo, em 1953, mostram que $50 \%$ dos negros e $40 \%$ dos mestiços eram analfabetos. Quanto aos estudantes universitários os mestiços alcançavam um percentual de $33 \%$, enquanto os negros atingiam apenas $2,9 \%{ }^{58}$.

Domingos e Keller, em 1956, publicaram um guia sobre Salvador, na qual se destacava a localização das classes na cidade: as "classes mais abastadas" residiam na Vitória, Graça, Barra, Barra Avenida e ao longo das praias atlânticas; as "classes médias" residiam em Nazaré, Barbalho, Santo Antônio e Soledade; enquanto que a "população pobre" se concentrava na Liberdade, São Caetano, Uruguai, Massaranduba e Penha ${ }^{59}$.

Em 1960 a população de Salvador atinge 655.735 habitantes, sendo $61 \%$ de origem migratória ${ }^{60}$.

\section{0-2005 - Metropolização: Acessibilidade e americanização}

A implantação, no início dos anos 70 do sistema de avenidas de vale (juntamente com a abertura da Avenida Paralela e a construção do Centro Administrativo) causou uma revolução urbanística em Salvador, ampliando a acessibilidade entre as diferentes partes da cidade.

Os impactos indiretos dos investimentos realizados no Pólo Petroquímico transformaram Salvador, sobretudo com a implantação de cinco shoppings centers e com a ampliação da verticalização da cidade, além do aparecimento dos condomínios fechados.

Em 1970, a população ultrapassa um milhão de habitantes ( $53 \%$ ainda devido às migrações ${ }^{61}$ ). Nos anos 70 (e início dos 80) foram construídas cerca de 20.000 unidades em conjuntos habitacionais no Miolo, denominação da parte central da península.

Em 1980 a população da cidade atinge 1.502.000 habitantes. As desigualdades permaneceram: nesse ano, da população ocupada recebendo até um salário mínimo, $46,2 \%$ eram negros, $18,3 \%$ eram pardos e $8,7 \%$ brancos. Os sub-distritos que tiveram sua renda abaixo da média da R.M.S. (15.671 cruzeiros) foram os seguintes: Penha (14.190), Santo Antônio (13.051), Periperi (12.871) Sé e Passo (12.719), Plataforma (11.409), Paripe (11.151), São Caetano (10.630), Conceição da Praia e Pilar (10.033), São Cristóvão (9.804), Pirajá (9.607), Valéria (8.572) e Maré (4.800) ${ }^{62}$,. Todos, portanto, situados no centro e ao norte da cidade.

Nos anos 80, ocorreram 37 invasões (três erradicadas), e oito loteamentos populares foram implantados ${ }^{63}$. Com as reformas realizadas no Pelourinho, Salvador passa a ser considerada, em 1985, "Patrimônio Histórico da Humanidade", mas a quase totalidade da população pobre da área é indenizada e dispersa.

Em 1991, a população da cidade atinge 2.075.000 habitantes. No censo de 2000, a população alcança 2.243.107 residentes, tendo sido estimada, pelo IBGE, em 2.631.831 habitantes em 2004. 


\section{Conclusões}

De cidade colonial, Salvador sofre as reformas para aproximá-la do padrão europeu e, finalmente, tem seu padrão revolucionado segundo o modelo norteamericano, apesar de manter as grandes desigualdades sociais e uma maioria de pobres urbanos. Neste sentido, o modelo norte-americano é parcial e invertido, permanecendo as divisões centro-periferia, mas com a pobreza localizada, em sua maioria, no entorno precário da cidade, em conjuntos habitacionais, loteamentos irregulares, e, sobretudo, em terrenos invadidos, refletindo no espaço a persistência e a ampliação da pobreza urbana.

O caso de Salvador indica que é melhor trabalhar com a noção de pobreza urbana do que tentar utilizar noções elaboradas em outros contextos, como as de "marginal", de "underclass" ou de "excluído", sobretudo numa sociedade onde a pobreza não é uma questão de minorias ${ }^{64}$.

\section{Notas}

${ }^{1}$ Embora sem a pretensão de esgotar o assunto.

2 Vasconcelos, 2002.

3 Bronislaw Geremek (1994), in Schwartzman, 2004:57-58.

${ }^{4}$ Polanyi, 2000:129.

${ }^{5}$ Ibidem, p.262.

${ }^{6}$ Castel, 1998:283.

7 Conforme Etienne et ali, 1998.

8 Ibidem.

${ }^{9}$ É interessante observar a impossibilidade de aplicar as noções de "marginalidade" e de "exclusão" no caso norte-americano, na medida em que os pobres e as minorias estão localizadas perto das áreas centrais das cidades.

${ }^{10}$ Fassin, 1996:264.

${ }^{11}$ Fassin, 1996.

12 Lewis, 1968:xlv-xlviii.

13 Kowarick, 1977:13.

${ }^{14}$ Ibidem, p. 34.
15 Ib., p. 168.

${ }^{16}$ Perlman, 1976:242-243.

17 Wacquant, 2001:97.

18 Wacquant, 1996.

${ }^{19}$ Ibidem, p. 249.

${ }^{20}$ Wacquant, 2001:10-11.

${ }^{21}$ Eurostat, 1995 in Paugan, 1996:391.

22 Paugan, 1996:393; 395; 399; 401.

${ }^{23}$ Santos, 1978:8.

${ }^{24}$ Brunet et ali, 1993:411.

${ }^{25}$ Grupo Aduar, 2000:46.

26 Vasconcelos, 2002.

27 Cardim (1978), in Vasconcelos, 2002:47.

${ }^{28}$ Anchieta (1988), in Vasconcelos, 2002:43.

29 Ruy (1953) e Freitas (1977), in Vasconcelos, 2002:44.

${ }^{30}$ A. C. 1641-1649:32, in Vasconcelos, 2002.

${ }^{31}$ Schwartz (1988), in Vasconcelos, 2002.

32 Amaral, in Accioli (1937), in Vasconcelos 2002. 
33 Tavares (1979), in Vasconcelos, 2002.

${ }^{34}$ AUM 8.440:254, in Vasconcelos, 2002.

35 Quanto à situação dos homens livres no período escravista e dos agregados rurais ver Franco (1983).

${ }^{36}$ Costa (1965:55), in Vasconcelos, 2002.

${ }^{37}$ Ibidem.

38 Campos (1987), in Vasconcelos, 2002.

39 Vilhena (1969), in Vasconcelos, 2002:146-147.

40 Ibidem, p. 133.

${ }^{41}$ Ibidem, p. 170.

42 Lindley (1969), in Vasconcelos, 2002:157.

43 Tollenare (1956), in Vasconcelos, 2002:173.

${ }^{44}$ Graham (1990), in Vasconcelos, 2002:158.

${ }^{45}$ Verger (1967) e Reis (1986) in Vasconcelos, 2002.

46 CPE (1978) e Magalhães (1848), in Vasconcelos, 2002:193.

47 Wetherell (1972), in Vasconcelos, 2002:191 e 192.

48 Mattoso (1992), in Vasconcelos, 2002: 227 e 229.

${ }^{49}$ Ibidem (1979), in Vasconcelos, 2002:227.
${ }^{50}$ Fraga Filho (1996), in Vasconcelos, 2002:153.

51 Martinez (1979), in Vasconcelos, 2002:217.

52 Wetherell (1972), in Vasconcelos, 2002:223 e 230.

53 Mouchez (1864), in Vasconcelos, 2002:233-234.

${ }^{54}$ Pierson (1976), in Vasconcelos, 2002:279 e 280.

55 DGE (1926), in Vasconcelos, 2002:300.

56 PMS (1977), in Vasconcelos, 2002:324.

57 Santos (1959), in Vasconcelos, 2002:319.

58 Azevedo (1953), in Vasconcelos, 2002:318.

59 Domingos e Keller (1958), in Vasconcelos, 2002:321.

${ }^{60}$ Souza (1980), in Vasconcelos, 2002:324.

61 Ibidem, p. 353.

62 Vasconcelos (1985), in Vasconcelos, 2002:351 e 352.

${ }^{63}$ CPE (1980), in Vasconcelos, 2002:354.

${ }^{64}$ A Bahia teria o maior contingente absoluto de famílias pobres no Brasil. Ver www.mds.gov.br/ secretarias/cadunico-uf.pdf (Consulta em 16/05/ 2006).

\section{Bibliografia}

BOURDIEU, Pierre (coord.) A Miséria do Mundo. Petrópolis: Vozes, 2003 (orig. 1993).

BRUNET, R.; FERRAS, R.; THERY, H. Les mots de la géographie, Montpellier, Reclus; Paris: La Documentation Française, 1993.

CASTEL, Robert. As Metamorfoses da Questão Social. Uma crônica do salário. Petrópolis: Vozes, 1998 (orig. 1995).

ETIENNE, J. et ali. Dicionário de Sociologia. Lisboa: Paralelo, 1998.

FASSIN, Didier. «Marginalidade et marginados. La construction de la pauvreté urbaine em Amérique Latine», in Paugam, S. (dir.) L'exclusion.
L'état des savoirs. Paris: La Decouverte, 1996, p.263-271.

FRANCO, Maria Sylvia de Carvalho. Homens Livres na Ordem Escravocrata. São Paulo: Kairos, 1983.

GRUPO ADUAR, Diccionario de geografía urbana, urbanismo y ordenación del territorio. Barcelona: Ariel, 2000.

KOWARICK, Lúcio. Capitalismo e Marginalidade na América Latina. Rio de Janeiro: Paz e Terra, 1977.

LEWIS, Oscar. La Vida. New York: Vintage, 1968 [1965].

PAUGAM, Serge. "Pauvreté et exclusion. La force des contrastes nationaux", in Paugam, S. (dir.) 
L'exclusion. L'état des savoirs. Paris: La Decouverte, 1996, p. 389.404.

PERLMAN, Janice E. The Myth of Marginality. Berkeley: Univ. of California Press, 1976.

POLANYI, Karl. A Grande Transformação: as origens da nossa época. Rio de Janeiro: Campus, 2000 (orig. 1944).

SANTOS, Milton. Pobreza Urbana. São Paulo: Hucitec, Recife: MDU, 1978.

SCHWARTZMAN, Simon. Pobreza, exclusão social e modernidade: uma introdução ao mundo contemporâneo. São Paulo: Augurium, 2004.

VASCONCELOS, Pedro de A. Salvador: transformações e permanências (1549-1999). Ilhéus, 2002.

WAQUANT, Loïc. Os Condenados da Cidade. Rio de Janeiro : Revan, Fase, 2001.

WACQUANT, Loïc. «L'underclass urbaine dans I'imaginaire social et scientifique americain», in Paugam, S. (dir.) L'exclusion. L'état des savoirs. Paris: La Decouverte, 1996, p.248-262. 
